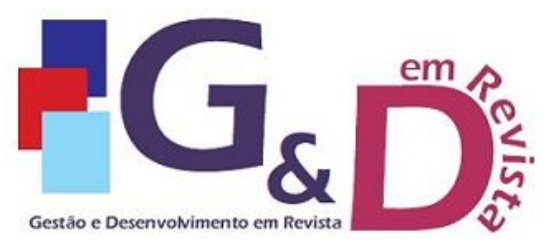

Gestão e Desenvolvimento em Revista V. 8, N. 2, jul-dez/2021, p. 68-89.

ISSN online: $2446-8738$

Artigo recebido em: 27/07/2021

Artigo aprovado em: 25/01/2022

\title{
APLICAÇÃO DO PROKNOW-C PARA SELEÇÃO E ANÁLISE DE UM PORTFÓLIO BIBLIOGRÁFICO SOBRE APLICAÇÃO DOS RECURSOS DA TECNOLOGIA 4.0
}

\author{
Thiago Siqueira de Souza \\ Graduado em Engenharia de Produção pelo Centro Universitário Salesiano - UniSales. \\ E-mail: thiagossiqueira@outlook.com
}

\section{Flávio Lúcio Santos de Carvalho}

Mestre em Engenharia Metalúrgica e de Minas pela Universidade Federal de Minas Gerais (UFMG). Atualmente é docente dos cursos de Engenharia Civil e Engenharia de Produção do Centro Universitário Salesiano - UniSales.

E-mail: fcarvalho@ucv.edu.br

\section{Thiara Cezana Gomes}

Doutoranda em Engenharia Ambiental pela Universidade Federal do Espírito Santo - UFES.

E-mail: thiaracezana@gmail.com

\section{Marcos Wagner Jesus Servare Junior}

Doutorando em Engenharia Elétrica pela Universidade Federal do Espírito Santo e Coordenador dos cursos de Engenharia Civil e Engenharia de Produção do Centro Universitário Salesiano - UniSales. E-mail: marcos.servare@salesiano.br

\section{Resumo \\ O objetivo do artigo é aplicar o método ProKnow-C como método de pesquisa e análise quantitativa de artigos com reconhecimento científico e de relevância para o tema Aplicação dos Recursos da Tecnologia 4.0 sob a ideia de métodos de aplicação. Para tal, fez-se uso de busca e seleção sistemática de artigos pelo método ProKnow-C, realizando técnicas de análise bibliométrica e obtendo o que há de mais relevante no âmbito do tema de pesquisa. O método utilizado permitiu a construção do portfólio bibliográfico contemplando artigos reconhecidos cientificamente e publicados recentemente. Nesse contexto, para se chegar ao portfólio final foram aplicados alguns filtros, a fim de evidenciar características em comum, por meio do ano de publicação (a partir de 2015); artigos não repetidos; alinhamento do título; reconhecimento científico; autores com reconhecimento e, por fim, resumo alinhado. Ao final, um portfólio de 22 artigos foi obtido, sendo este constituído em sua totalidade por estudos publicados no Enegep.}

Palavras-chave: manufatura avançada; planejamento e controle; Proknow-C; tecnologia 4.0; internet das coisas (loT); big data; computação na nuvem; RFID.

\begin{abstract}
The objective of the article is to apply the ProKnow-C method as a research method and quantitative analysis of articles with scientific recognition and relevance to the topic of Application of Technology Resources 4.0 under the idea of application methods. For this purpose, systematic search and selection of articles by the ProKnow-C method was used, performing bibliometric analysis techniques and obtaining what is most relevant in the scope of the research theme. The method used allowed the construction of the bibliographic portfolio including scientifically recognized and recently published articles. In this context, to arrive at the final portfolio, some filters were applied in order to highlight common characteristics through the year of publication (from 2015 onwards); non-repeated articles; title alignment; scientific recognition; authors with recognition and, finally, an aligned abstract. In the end, a portfolio of 22 articles was obtained, which is made up entirely of studies published in Enegep.
\end{abstract}

Keywords: advanced manufacturing; planning and control; Proknow-C; technology 4.0; internet of things (loT); big data; cloud computing; RFID. 


\section{INTRODUÇÃO}

Desde a Revolução Industrial do século XVIII, a produção industrial vem passando por constantes mudanças, visto que o seu desenvolvimento é voltado à fábrica inteligente. Entretanto, se percebe que a natureza onipresente, ligada diretamente a quarta revolução industrial, suas tecnologias de comunicação são utilizadas para interligar as operações de manufatura, produtos inteligentes e força humana (FRANCO et al., 2020, p. 02).

A indústria 4.0 se refere a ambientes com alta capacidade de inteligência, onde a tecnologia da informação tem a capacidade de se conectar entre os mais diversos setores da fábrica de forma autônoma e em tempo real, propondo uma melhor maneira de gerenciar o chão de fábrica (FRANCO et al., 2020, p. 02). Rüssmann et al. (2015) ressaltam que as "tecnologias responsáveis por construir e sustentar a base da quarta revolução industrial, são: big data; computação em nuvem; integração horizontal e vertical de sistemas; internet das coisas [...]", além de contar com a tecnologia RFID.

Os recursos das tecnologias 4.0 como ferramenta de melhoria, são utilizados com objetivo de otimizar qualquer que seja o processo. Sua aplicação aumenta a produtividade, bem como, reduz custos e retrabalhos, já que sua função é utilizar meios digitais dentro do processo, aumentando a capacidade de produção e diminuindo o esforço humano.

Diante desse contexto, este artigo tem como objetivo propor uma revisão sistemática da literatura a partir da análise sistêmica e bibliográfica dos artigos levantados. Utilizando a metodologia ProKnow-C foi possível realizar a revisão de artigos de congressos e revistas a partir de 2015, onde foi possível analisar e identificar, por meio das palavras-chave, artigos mais relevantes para 0 desenvolvimento do campo de estudos em questão.

O trabalho está dividido em: Seção 1 contempla a abordagem introdutória a respeito do tema; Seção 2 apresenta o referencial teórico para a realização da pesquisa com base na metodologia ProKnow-C; Seção 3 aborda a aplicação da metodologia, assim, estão descritos os procedimentos a respeito da utilização do ProKnow-C, análise bibliométrica e sistêmica; Seção 4 apresenta as considerações finais. Por fim, este trabalho apresenta as referências bibliográficas utilizadas. 


\section{METODOLOGIA PROKNOW-C}

A revisão sistemática de um tema exige que pesquisadores definam, identifiquem, selecionem e analisem a literatura relevante. O método ProKnow-C de Ensslin et al. (2010) tem sido amplamente usado para apoiar revisões sistemáticas (DE CARVALHO et al., 2020). Ensslin et al. (2010) organizaram o método em quatro etapas, conforme Figura 1.

Figura 1 - Etapas do processo ProKnow-C

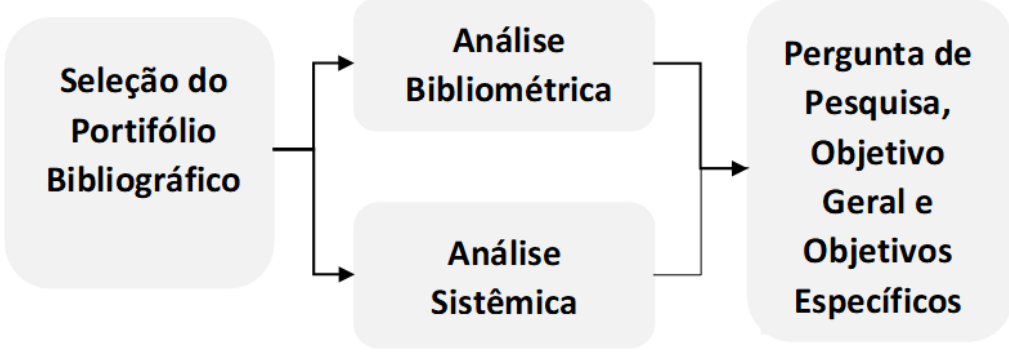

Fonte: Adaptado de Ensslin et al. (2010)

Neste estudo, o foco se dará nas três etapas iniciais, detalhadas a seguir.

a) Seleção de Portfólio Bibliográfico: nesta etapa, deve-se realizar a busca por material científico nas bases de dados de maneira sistematizada. Inicialmente, define-se o tema e as palavras-chave. Em seguida, as bases de dados são selecionadas, depois da busca por artigos científicos, aplica-se uma sequência de filtros para gerar o portfólio bibliográfico e alcançar artigos com maior relevância para o tema. Os filtros aplicados, foram: artigos repetidos no portfólio, alinhamento dos títulos e reconhecimento científico. Em seguida, os artigos obtidos devem ser analisados quanto a disponibilidade e coerência com tema, por meio da leitura dos resumos.

b) Análise Bibliométrica: nesta fase, é importante contabilizar os dados estatísticos do conjunto de artigos obtidos na etapa (a), através de parâmetros como: palavras-chave, autores, ano, periódicos e citações. Dessa forma, identificamse dois grupos de indicadores: o primeiro relacionado aos artigos do portfólio e o segundo, às referências dos artigos do portfólio, onde são desenvolvidas métricas referentes às repetições dos artigos, citações, materiais, origem e periódicos. 
c) Análise Sistêmica: nesta etapa deve-se analisar as barreiras encontradas e os resultados dentro de cada artigo do portfólio. Dessa forma, é possível enxergar as dificuldades encontradas para aplicação das ferramentas, os desafios encontrados para implantação da tecnologia 4.0 e qual a melhor forma de se aplicar os recursos da tecnologia 4.0.

\section{APLICAÇÃO DA METODOLOGIA PROKNOW-C}

A seguir encontra-se o detalhamento do processo de seleção do portfólio e análise bibliométrica, evidenciando a utilização do método ProKnow-C para o tema: aplicação dos recursos da tecnologia 4.0.

\subsection{SELEÇÃO DO PORTFÓLIO BIBLIOGRÁFICO}

\subsubsection{Seleção do banco de artigos brutos}

Essa seleção consiste em buscar artigos que tenham relação com o tema escolhido. Nessa busca foram considerados artigos em português, publicados em revistas e congressos de grande referência da área da Engenharia de Produção.

- Definição das palavras-chave (PC): para definição das PCs foi necessário, a princípio, analisar aquelas com maior coerência ao tema. Com isso, foram escolhidas: manufatura avançada, planejamento e controle, tecnologia 4.0, internet das coisas (IoT), big data, computação na nuvem e RFID (identificação por radiofrequência).

- Definição do Banco de Dados: para esta seleção foram utilizadas as fontes de maior referência na área de Engenharia de Produção no Brasil, a listar: ENEGEP (Encontro Nacional de Engenharia de Produção), SIMPEP (Simpósio de Engenharia de Produção), PO (Produção Online) e BJPE (Brazilian Journal of Production Engineering). Em seguida, as PCs foram alinhadas e feito a busca em cada base. Usou-se como critério nas buscas em cada base de dados, artigos publicados acima do ano de 2015 e artigos que tivessem as PCs em seus títulos. A Figura 2 ilustra as bases relacionadas e o número de artigos encontrados em cada uma delas.

Figura 2 - Bases de dados e número de artigos encontrados 


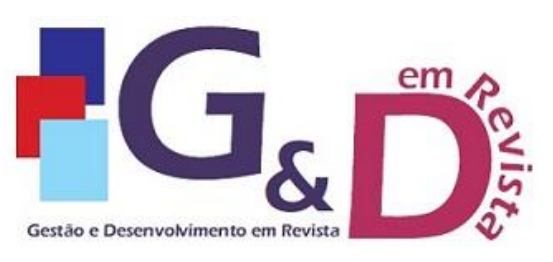

Gestão e Desenvolvimento em Revista V. 8, N. 2, jul-dez/2021, p. 68-89.

ISSN online: $2446-8738$

Artigo recebido em: 27/07/2021

Artigo aprovado em: 25/01/2022

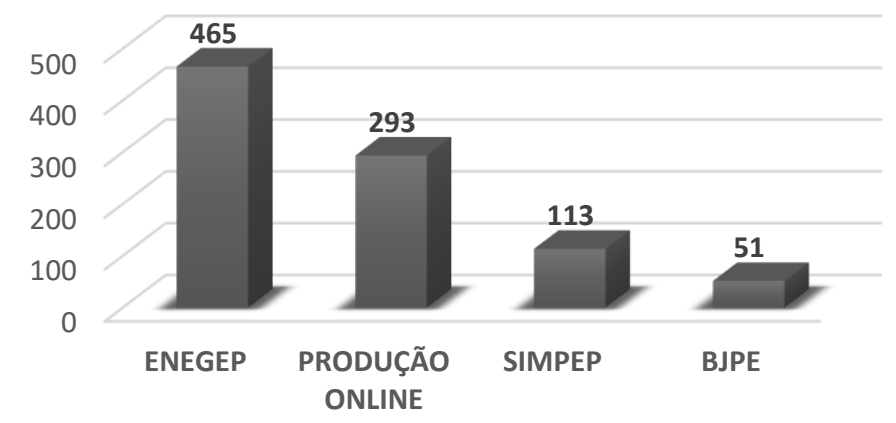

- Teste de aderência das palavras-chave: nesta etapa é necessário verificar se as PCs estão alinhadas conforme os artigos e tema da pesquisa. No presente estudo, a maioria das PCs se mostraram bem alinhadas com o tema, exceto a PC "planejamento e controle" que, apesar do grande volume de resultados, apresentou muitos títulos desalinhados ao tema aplicação dos recursos da tecnologia 4.0.

Como resultado da etapa de seleção dos artigos brutos, foram obtidas sete palavras-chave e as bases para a busca de artigos. Ao final, o banco de artigos brutos (BAB) contemplou um total de 42 artigos reconhecidos cientificamente.

\subsubsection{Filtragem do banco de artigos brutos (BAB)}

O filtro do BAB tem por objetivo selecionar artigos que tenham maior relação com o tema proposto e grande relevância. Para isso, os artigos devem passar por alguns filtros para, posteriormente, originar o portfólio bibliográfico.

- Filtro do $B A B$ de artigos não repetidos: para iniciar, é necessário eliminar do $B A B$ os artigos repetidos, isso é, excluir artigos que venha existir em mais de uma base de dados. Nessa fase foi utilizado o Microsoft Excel como ferramenta de auxílio, software com várias funcionalidades, no qual foi possível importar as informações dos artigos selecionados nas bases utilizadas (palavras-chave, título, autores, ano). Dessa forma, para identificar os artigos duplicados foi feita a classificação de A-Z, facilitando a filtragem. Nessa pesquisa, $14 \%$ dos artigos estavam duplicados. Sendo assim, o BAB passou de 924 para 795 artigos brutos não repetidos;

- Filtro do BAB de artigos alinhados quanto ao título: nesse filtro foi realizada a leitura integral dos títulos dos 795 artigos e, posteriormente, excluídos aqueles que não tivessem nenhuma relação com recursos da tecnologia 4.0. Sendo assim, foram 
eliminados 652 não relacionados ao tema. O BAB de artigos não repetidos, então, ficou com 143 artigos, ou seja, 17,9\% do total.

- Filtro do BAB quanto ao reconhecimento científico: nessa etapa é necessário contabilizar o número de citações de cada artigo. Foram utilizadas as informações disponíveis no Google Acadêmico que disponibiliza o número de vezes que cada artigo foi citado em outros documentos. Dessa forma, foi possível demonstrar a representatividade de cada estudo e, posteriormente, o percentual acumulado que os artigos mais citados representam. Conseguinte, para o estudo em questão, 42 artigos foram selecionados. Primeiramente, foi utilizado a classificação através do diagrama de Pareto, onde os 90\% representam artigos com maior expressão e relevância de acordo com a quantidade de citações, visto que a quantidade de citações indica ser um artigo confiável e reconhecido, vale ressaltar que o critério utilizado foi a partir de pesquisas no google acadêmico. Nesse sentido, 7 artigos foram responsáveis pelos $90 \%$ que, nesse caso, artigos com até sete citações, encaixados como artigos com reconhecimento científico. Como resultado, obteve-se uma base com 7 artigos mais citados, 1 artigo com autores com reconhecimento, isto é, possui o mesmo autor dos artigos da base e 34 como artigos recente, uma vez que artigos muito recentes não possuem ou possuem poucas citações, ou seja, tem pouco tempo de publicação, logo, não são tão acessados.

- Filtro com relação a disponibilidade: nessa etapa, a base de 42 artigos, passa pela filtragem de disponibilidade desses documentos para download. Visto que, há periódicos que exigem pagamento para acesso aos artigos, além de restrições de determinadas bases (sites fechados). Todavia, os 42 artigos tiveram disponibilidade para download.

- Seleção da base de artigos com: reconhecimento científico, autores com reconhecimento, artigo recentes, e quanto ao resumo: a base com 42 artigos passou por estes filtros, isto é, ver os que tiveram maior relação com o tema de recursos da tecnologia 4.0. Dentro desse contexto, dos 42 artigos da base apenas 22 artigos estavam com o resumo alinhado com o tema. Como resultado, obteve-se 6 artigos com reconhecimento científico e 16 artigos publicados recentemente.

- Filtro com relação ao alinhamento do texto completo: nessa etapa foi finalizado o processo de seleção. Esse filtro consiste na leitura integral dos artigos alinhados e disponíveis. Para o estudo em questão, os 22 artigos estavam alinhados com a 


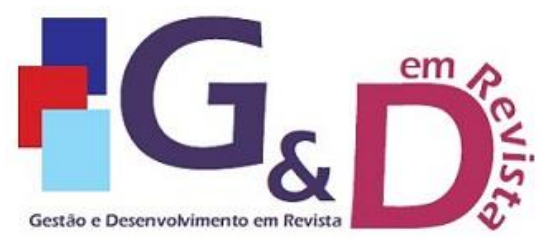

Gestão e Desenvolvimento em Revista V. 8, N. 2, jul-dez/2021, p. 68-89.

ISSN online: $2446-8738$

Artigo recebido em: 27/07/2021

Artigo aprovado em: 25/01/2022

forma de aplicação, métricas e tema proposto, tendo relação direta com o tema recursos da tecnologia 4.0 .

Por fim, o portfólio bibliográfico foi formado contemplando 22 artigos relevantes, alinhados ao tema e com reconhecimento científico. O portfólio pode ser observado na Quadro 1.

Quadro 1 - Portfólio bibliográfico sobre aplicação dos recursos da tecnologia 4.0 (mai/2021)

\begin{tabular}{|c|c|c|c|c|c|}
\hline \# & Autores & Título & Origem & Ano & Citações \\
\hline 1 & $\begin{array}{l}\text { PLANEJAMENTO } \\
\text { E CONTROLE }\end{array}$ & $\begin{array}{l}\text { Planejamento e controle da manutenção aplicados } \\
\text { ao processo de manufatura no ramo alimentício }\end{array}$ & ENEGEP & 2015 & 7 \\
\hline 2 & TECNOLOGIA 4.0 & $\begin{array}{l}\text { Indústria 4.0: contribuições para setor produtivo } \\
\text { moderno }\end{array}$ & ENEGEP & 2017 & 6 \\
\hline 3 & TECNOLOGIA 4.0 & $\begin{array}{l}\text { Etapas para implantação da indústria 4.0: uma } \\
\text { visão sob aspectos estratégicos e operacionais }\end{array}$ & ENEGEP & 2017 & 3 \\
\hline 4 & TECNOLOGIA 4.0 & A busca de uma identidade para a indústria 4.0 & ENEGEP & 2017 & 2 \\
\hline 5 & TECNOLOGIA 4.0 & $\begin{array}{l}\text { A indústria } 4.0 \text { na perspectiva da engenharia de } \\
\text { produção no brasil: levantamento e síntese de } \\
\text { trabalhos publicados em congressos nacionais }\end{array}$ & ENEGEP & 2017 & 2 \\
\hline 6 & TECNOLOGIA 4.0 & $\begin{array}{l}\text { Gestão da manutenção industrial em transição } \\
\text { para a indústria 4.0: controle mobile, } \\
\text { considerações sobre esta nova tecnologia }\end{array}$ & ENEGEP & 2017 & 2 \\
\hline 7 & TECNOLOGIA 4.0 & $\begin{array}{l}\text { A importância da manutenção na indústria do } \\
\text { petróleo \& gás }\end{array}$ & ENEGEP & 2020 & 0 \\
\hline 8 & $\begin{array}{l}\text { PLANEJAMENTO } \\
\text { E CONTROLE }\end{array}$ & $\begin{array}{l}\text { Análise do planejamento e controle da produção } \\
\text { em uma empresa prestadora de serviços } \\
\text { terceirizados de manutenção segundo o modelo } \\
\text { MRP II }\end{array}$ & ENEGEP & 2020 & 0 \\
\hline 9 & $\begin{array}{l}\text { INTERNET DAS } \\
\text { COISAS }\end{array}$ & $\begin{array}{l}\text { Aplicação das tecnologias da indústria } 4.0 \text { na } \\
\text { engenharia de produção: uma revisão sistemática } \\
\text { da literatura }\end{array}$ & ENEGEP & 2020 & 0 \\
\hline 10 & TECNOLOGIA 4.0 & $\begin{array}{l}\text { Aplicações da internet das coisas na indústria } \\
\text { brasileira: uma revisão sistemática }\end{array}$ & ENEGEP & 2020 & 0 \\
\hline 11 & $\begin{array}{l}\text { INTERNET DAS } \\
\text { COISAS }\end{array}$ & $\begin{array}{l}\text { As contribuições da internet das coisas na Co } \\
\text { criação de valor em serviços }\end{array}$ & ENEGEP & 2020 & 0 \\
\hline 12 & TECNOLOGIA 4.0 & $\begin{array}{l}\text { Conceitualização da indústria 4.0: uma análise } \\
\text { utilizando revisão sistemática da literatura }\end{array}$ & ENEGEP & 2020 & 0 \\
\hline 13 & $\begin{array}{l}\text { PLANEJAMENTO } \\
\text { E CONTROLE }\end{array}$ & $\begin{array}{l}\text { Desenvolvimento de indicadores e dashboard para } \\
\text { gestão da qualidade em uma indústria de produtos } \\
\text { eletrônicos }\end{array}$ & ENEGEP & 2020 & 0 \\
\hline 14 & TECNOLOGIA 4.0 & $\begin{array}{l}\text { Efeitos das abordagens de melhoria contínua no } \\
\text { uso de tecnologias } 4.0 \text { para a manufatura e } \\
\text { inovação }\end{array}$ & SIMPEP & 2020 & 0 \\
\hline 15 & TECNOLOGIA 4.0 & $\begin{array}{l}\text { Engenharia de serviços: os impactos da indústria } \\
4.0 \text { no contexto da Co criação de valor em serviços } \\
\text { industriais }\end{array}$ & ENEGEP & 2020 & 0 \\
\hline 16 & TECNOLOGIA 4.0 & $\begin{array}{l}\text { Estudo de aplicabilidade de internet of things por } \\
\text { smartphones: análise de movimentação de } \\
\text { usuários }\end{array}$ & ENEGEP & 2020 & 0 \\
\hline 17 & TECNOLOGIA 4.0 & $\begin{array}{l}\text { Gestão do conhecimento e indústria } 4.0 \text { : } \\
\text { competências requeridas aos profissionais } \\
\text { inseridos neste contexto }\end{array}$ & ENEGEP & 2020 & 0 \\
\hline 18 & BIG DATA & $\begin{array}{l}\text { Mineração de dados em gestão da manutenção: } \\
\text { uma análise bibliométrica em manifestos da } \\
\text { indústria de óleo e gás }\end{array}$ & SIMPEP & 2020 & 0 \\
\hline
\end{tabular}




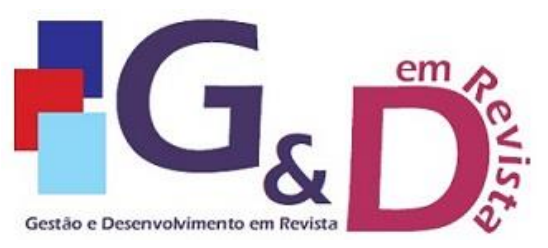

Gestão e Desenvolvimento em Revista V. 8, N. 2, jul-dez/2021, p. 68-89.

ISSN online: $2446-8738$

Artigo recebido em: 27/07/2021

Artigo aprovado em: 25/01/2022

\begin{tabular}{|c|c|c|c|c|c|}
\hline 19 & TECNOLOGIA 4.0 & $\begin{array}{l}\text { Modelos de maturidade para indústria } 4.0 \text { - } \\
\text { estudos de caso }\end{array}$ & ENEGEP & 2020 & 0 \\
\hline 20 & $\begin{array}{l}\text { INTERNET } \\
\text { COISAS }\end{array}$ & $\begin{array}{l}\text { O papel da internet das coisas (IOT) nas práticas } \\
\text { de manufatura ágil: uma análise da interação do } \\
\text { modelo conceitual de manufatura ágil com as } \\
\text { categorias de aplicativos da IOT }\end{array}$ & ENEGEP & 2020 & 0 \\
\hline 21 & BIG DATA & $\begin{array}{l}\text { O uso de big data analytics em sistemas de } \\
\text { medição de desempenho: uma revisão de estudos } \\
\text { empíricos }\end{array}$ & ENEGEP & 2020 & 0 \\
\hline 22 & TECNOLOGIA 4.0 & $\begin{array}{l}\text { Revisão sistemática do uso integrado das } \\
\text { tecnologias da indústria } 4.0 \text { e práticas da produção } \\
\text { enxuta }\end{array}$ & ENEGEP & 2020 & 0 \\
\hline
\end{tabular}

\subsection{ANÁLISE BIBLIOMÉTRICA DO PORTFÓLIO BIBLIOGRÁFICO}

Essa etapa foi dividida em duas partes, cujo objetivo foi fazer uma análise quantitativa dos artigos selecionados do portfólio, baseando-se nos dados numéricos: portfólio e referências do portfólio.

\subsubsection{Análise dos artigos do portfólio}

De acordo com a análise dos dados quantitativos dos artigos do portfólio bibliográfico, foram avaliados os seguintes pontos: palavras-chave mais utilizadas dentro do portfólio, relevância dos congressos no portfólio e quantidade de citação por congresso no portfólio.

- Análise das palavras-chave mais utilizadas dentro do portfólio: conforme ilustrado na Figura 3, nos 22 artigos selecionados foram observadas repetições das palavraschave dentro do portfólio. Notou-se que a palavra-chave com maior número de repetições foi "Indústria 4.0", evidenciando, assim, a relação dos artigos com o tema abordado. 


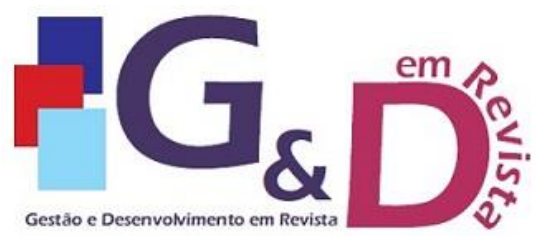

Gestão e Desenvolvimento em Revista V. 8, N. 2, jul-dez/2021, p. 68-89.

ISSN online: $2446-8738$

Artigo recebido em: 27/07/2021

Artigo aprovado em: 25/01/2022

Figura 3 - Palavras-chave dos artigos do portfólio

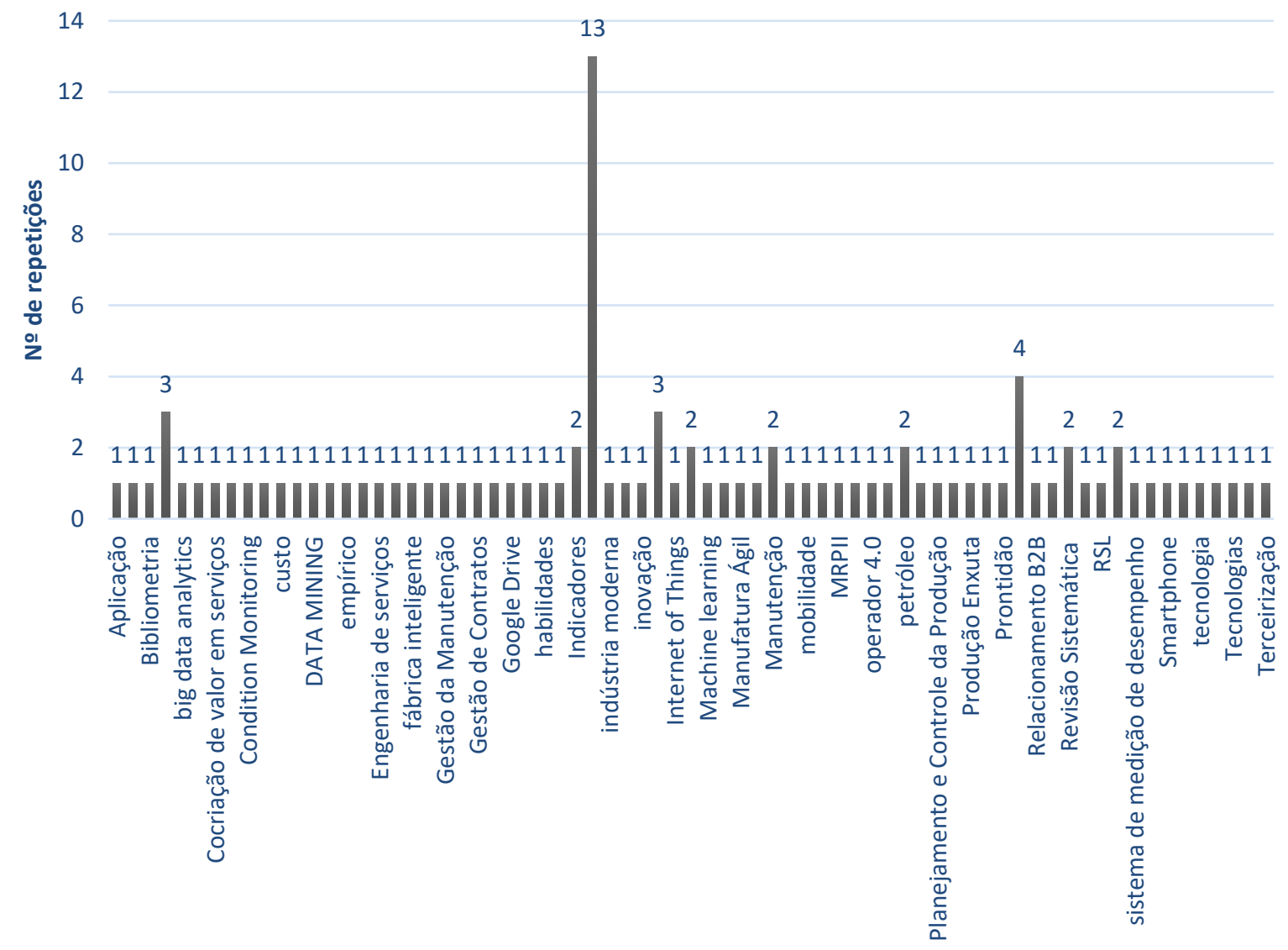

Fonte: Elaborado pelo autor (2021)

- Análise da relevância dos congressos no portfólio: dentre os 22 artigos selecionados, foi possível visualizar que 14 artigos foram publicados no ENEGEP no ano de 2020. Conforme a Figura 4, conclui-se que o ENEGEP tem maior expressão dentre as opções de congressos incluídas neste estudo.

Figura 4 - Relevância dos congressos no portfólio

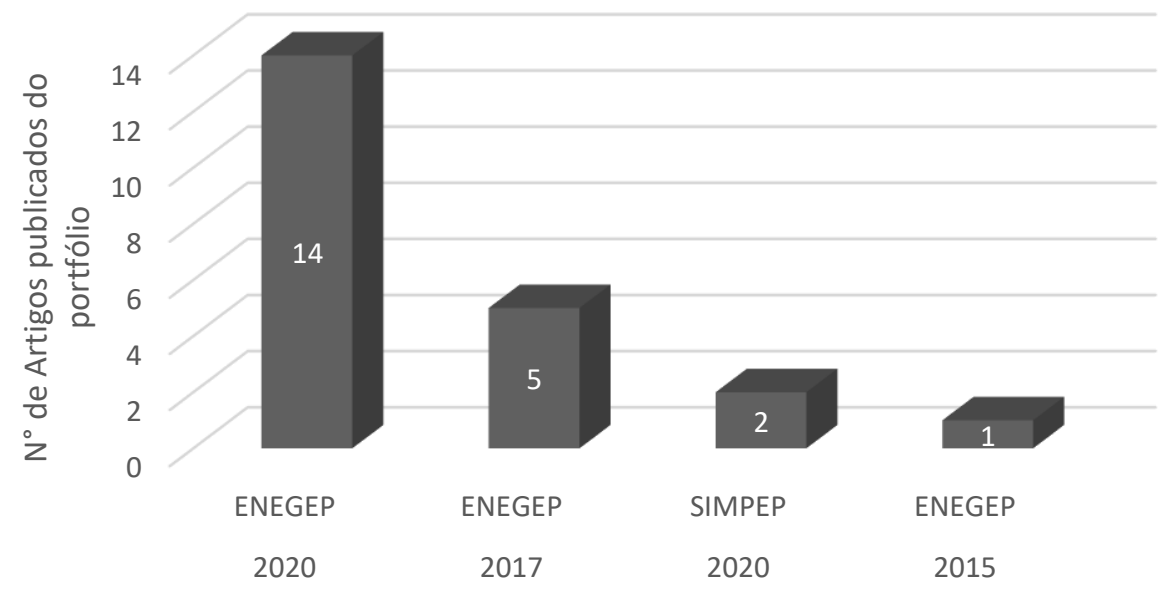


- Análise do reconhecimento científico pôr congresso do portfólio: conforme Figura 5, o ENEGEP teve maior reconhecimento científico no ano de 2017, com 15 citações, mostrando a relevância que trabalhos publicados no ano de 2017 tem para o portfólio bibliográfico.

Figura 5 - Reconhecimento científico pôr congresso do portfólio

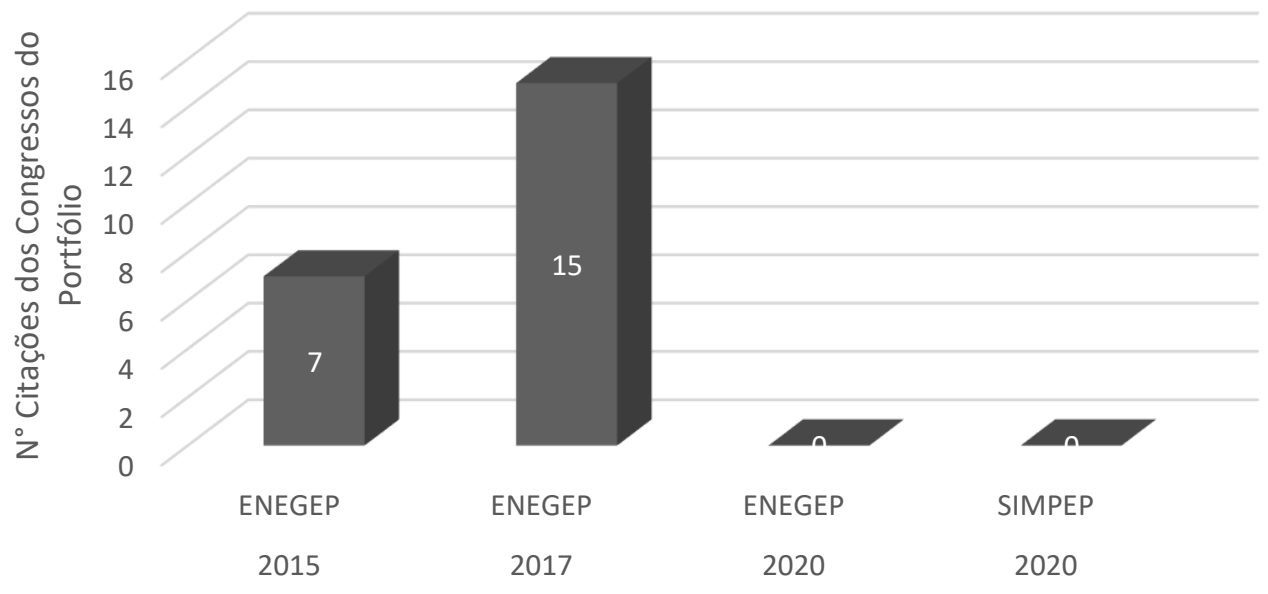

\subsubsection{Análise das referências dos artigos do portfólio}

Nessa etapa, os dados quantitativos dos artigos serão analisados de acordo com suas referências, isto é, foram extraídas as referências de cada artigo do portfólio. Dentre os 22 artigos do portfólio foram encontradas 549 referências.

- Análise do reconhecimento científico quanto aos títulos das referências do portfólio: através do número de citação de cada um dos artigos dentro das referências do portfólio, foi possível avaliar quais possuem maior reconhecimento científico, conforme Figura 6. 


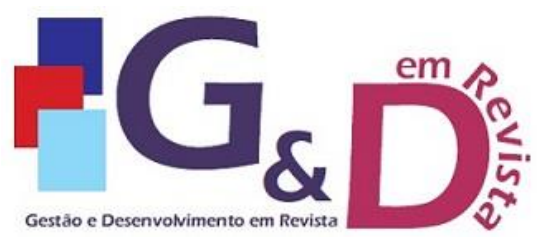

Gestão e Desenvolvimento em Revista V. 8, N. 2, jul-dez/2021, p. 68-89.

ISSN online: $2446-8738$

Artigo recebido em: 27/07/2021

Artigo aprovado em: 25/01/2022

Figura 6 - Reconhecimento científico quanto aos títulos das referências do portfólio

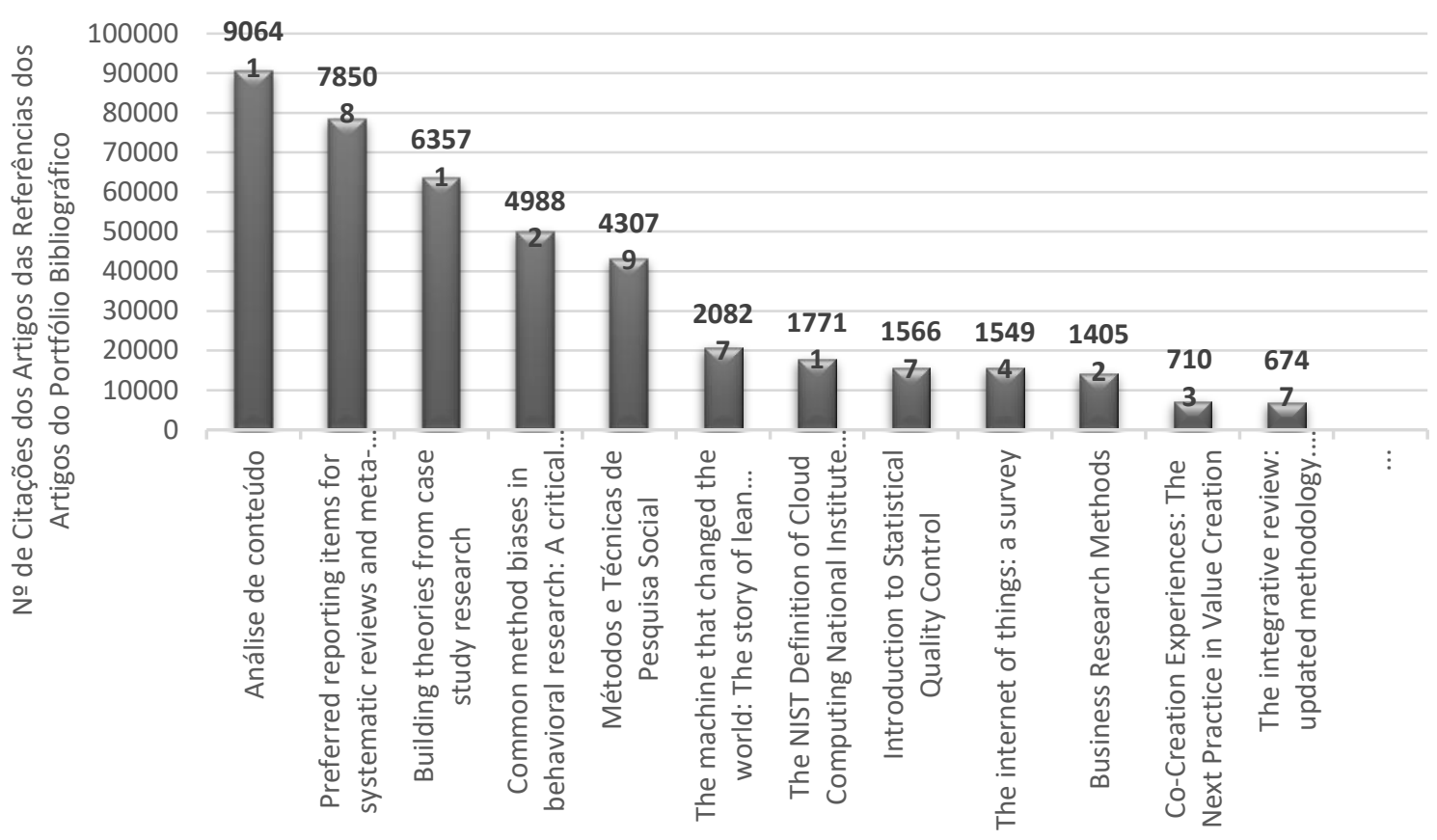

- Análise quanto a origem e o material utilizado: nas Figuras 7 e 8, respectivamente, foi possível avaliar os materiais utilizados e a origem dos mesmos para o desenvolvimento dos trabalhos.

Conforme ilustrado na Figura 7, dentro das referências do portfólio, o material encontrado com maior expressão foi do tipo "Artigo" com 369, evidenciando assim, a relação com o artigo científico desenvolvido, isto é, trabalhos desenvolvidos com a mesma linha de raciocínio e, consequentemente, obtendo a mesma base para se espelhar.

Figura 7 - Materiais utilizados

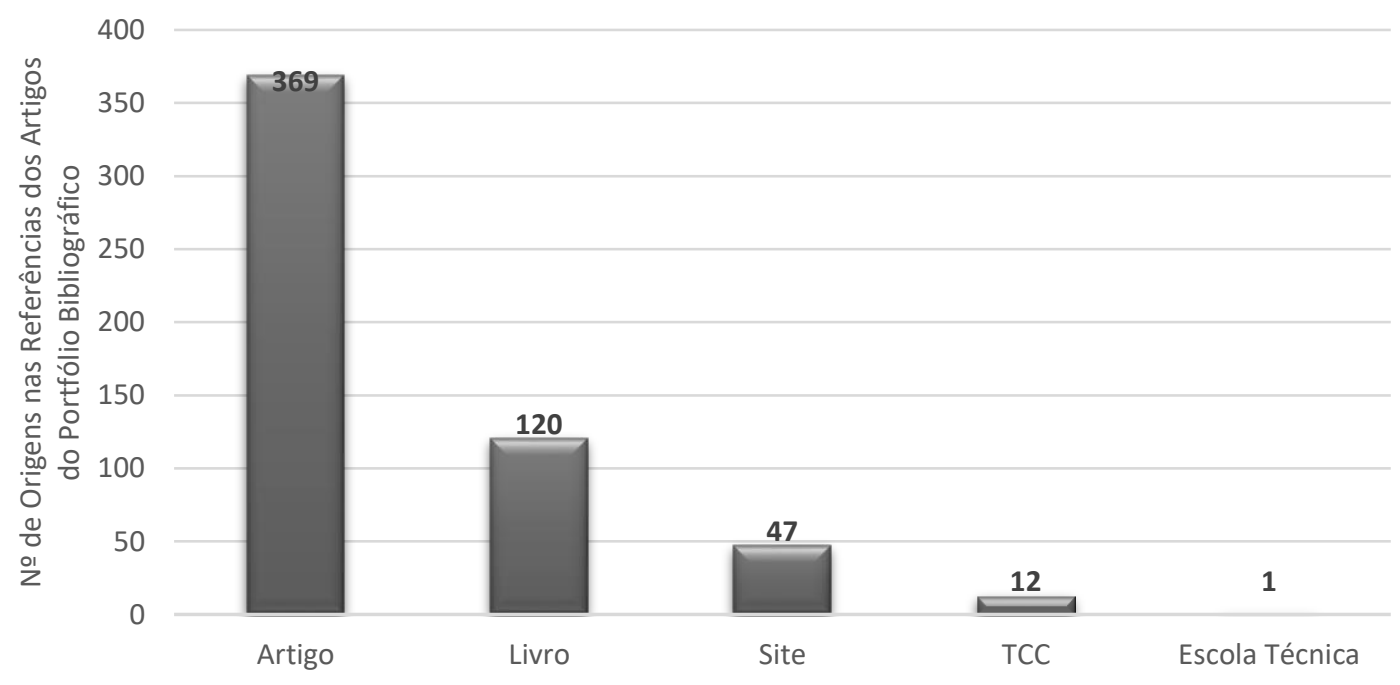


A figura 8, deixa evidente que dentre os trabalhos utilizados como base, 251 foram publicados como "Revista", fortalecendo a ideia de que, trabalhos nesse formato tem maior expressão em publicações.

Figura 8 - Origem dos materiais

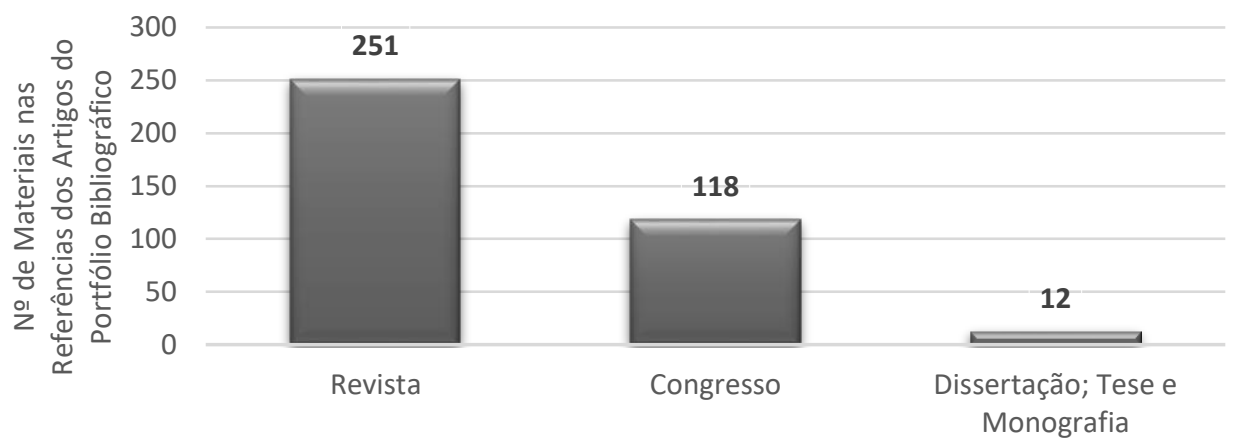

- Análise da relevância dos periódicos das referências: de 582 referências dos artigos do portfólio, 251 estão distribuídas em diferentes periódicos. Na Figura 9 é possível avaliar o periódico com maior relevância dentro das referências do portfólio. A Revista "International Journal of Production Research" foi referenciada 14 vezes dentre os artigos das referências. Desta forma, conclui-se que aplicação dos recursos da tecnologia 4.0 é um tema de grande interesse dentro dos periódicos.

Figura 9 - Periódicos das referências que mais se destacaram

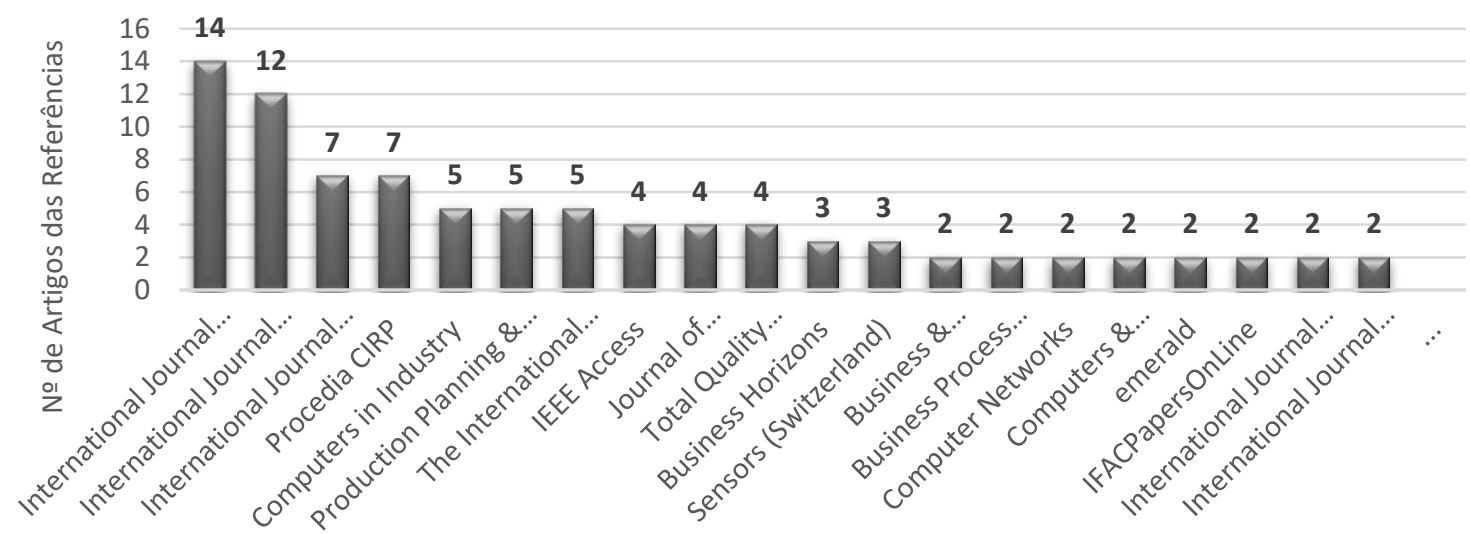

\subsection{ANÁLISE SISTÊMICA DO PORTFÓLIO BIBLIOGRÁFICO}

Feita a seleção do portfólio bibliográfico e análise bibliométrica dos artigos, conseguinte, foi realizada a análise sistêmica do portfólio com o objetivo de observar o que há em comum e enfatizar métodos aplicados, as diferentes dificuldades encontradas, impactos positivos e negativos com a aplicação de recursos da tecnologia 4.0. 
Queiroz (2015) desenvolveu um estudo de caso em uma empresa do segmento alimentício. Segundo o autor, por meio do "estudo de caso cria-se valor de outras formas de aplicação devido à sua forma de procura por informações, documentos, entrevistas, observação e interpretação das situações obtidas". O método foi desenvolvido através de coleta de dados, entrevista, acompanhamento de processos, documentário em fotos e análise de depoimentos de gestores, colaboradores. Desta forma, o artigo destaca que o objetivo foi assertivo, pois foi possível difundir, compreender e mostrar a implantação e as vantagens de se ter o Planejamento e Controle da Manutenção (PCM) nas empresas.

Cordeiro et al. (2017) com o intuito de estruturar uma proposta com etapas de implantação referente a Indústria 4.0, propuseram uma pesquisa exploratória, destacando a forma que funciona. Através das bases de dados científicos, congressos internacionais, relatórios governamentais e reportagem, foi possível reunir material teórico com o intuito de definir alguns conceitos centrais do âmbito da Indústria 4.0. Por fim, obteve-se um fluxo de atividades necessárias para a sua implantação nas empresas. Entretanto, os autores ainda destacaram que a principal vantagem de se utilizar o método de pesquisa bibliográfica é permitir ao pesquisador obter uma grande e variada base de informações, o que ajuda bastante para áreas de pesquisa.

Para Assad Neto et al. (2017), através da revisão integrativa na base de dados Scopus como ferramenta facilitadora, foi possível encontrar uma identidade para a indústria 4.0, onde se deu dentro de seis etapas, com o objetivo de filtrar as informações obtidas por meio da área de conhecimento, língua e ano de publicação. Dentro desse contexto, observou que a Alemanha liderou em número de publicações, resultado esperado, por ser o país responsável por definir o termo "Indústria 4.0" e por ser pioneiro no que diz respeito a exploração total de tecnologias de informação e comunicação. Todavia, o material desenvolvido fica à disposição para pesquisadores interessados no tema, através das palavras-chave que foram compiladas.

Sigahi e de Andrade (2017) destacaram a perspectiva da Engenharia de Produção sobre a Indústria 4.0 no Brasil e como tem evoluído as pesquisas dentro desse âmbito. Para isto, realizaram uma pesquisa organizada em seções com o objetivo de difundir as informações obtidas. Dentro dos congressos (ENEGEP e 
SIMPEP), foram analisados 89 artigos científicos e foi possível concluir que $72 \%$ dos estudos concentram-se nas áreas de Gestão da Produção, Gestão do Conhecimento Organizacional, Gestão do Produto e Pesquisa Operacional, Logística e Gestão da Cadeia Suprimentos e Distribuição. Através destes resultados, foi possível ressaltar que as indústrias pouco exploradas pela Engenharia de Produção podem representar uma porta de entrada para o estudo e pesquisa da Indústria 4.0.

Silva et al. (2017) abordaram a relação da gestão de manutenção com a tecnologia mobile. Onde foi analisado que ainda existem algumas barreiras para sua implantação, como a segurança das informações, resistência para adoção da mesma e o mau uso, embora tenham conhecimento de que a tecnologia 4.0 aparece como um novo paradigma de produção, aumentando e customização da produtividade e reduzindo custos. Para isto, utilizou-se a metodologia de pesquisa bibliográfica, onde foi possível abordar os requisitos base: técnicos, funcionalidades, vantagens e desvantagens e a partir dos resultados, sugerir uma melhor metodologia para implantação da tecnologia mobile.

Souza et al. (2017) expuseram a transição entre a terceira e a quarta revolução industrial, isto é, a digitalização como um dos principais focos nas indústrias. Desse modo, o artigo destacou os principais aspectos que garantem cada vez mais que essa transição seja necessária e as contribuições notadas com sua implantação. Por fim, concluiu-se que empresas que não investirem em infraestrutura para suportar a indústria 4.0, serão extintas pelo fato de não conseguir acompanhar e, automaticamente, competir com as demais concorrências.

Andrade et al. (2017) abordaram a indústria petrolífera, reconhecida como responsável por fornecer uma grande parcela de energia ao Brasil e a outros países. Dentro desse contexto, foram analisadas diferentes atividades realizadas dentro setor petrolífero: upstream, midstream e downstream, foram descritas e apresentados os principais riscos e dificuldades. Através do levantamento de seus riscos, foi possível enxergar o quão agressivo podem ser os impactos dos acidentes dessa indústria, dentre isso, viu-se a necessidade dos ativos obterem confiabilidade operacional, com o objetivo de reduzir a probabilidade de grandes acidentes $\mathrm{e}$ aumentar a disponibilidade dos mesmos. Além disso, o trabalho também abordou os requisitos empregados pelo setor de manutenção dentro do segmento destacando o 
uso de alguns recursos da tecnologia 4.0 na cadeia do petróleo. Apesar de ser pouco aplicado, é visto com bons olhos no que diz respeito ao monitoramento dos equipamentos e sua vida útil.

Bonamigo et al. (2020) evidenciaram a cocriação de valor e a codestruição de valor entre as empresas, isto é, da mesma forma em que a cocriação de valor vem crescendo a codestruição de valor vem logo atrás, que se dá de forma conjunta, onde empresas do mesmo âmbito industrial se unem com a finalidade se fortificar no mercado. Ainda Bonamigo et al. (2020) citam em seu estudo que os recursos advindos da Indústria 4.0 são apontadas na literatura como ferramenta de mitigação dessa codestruição de valor em serviços industriais.

Desta forma, através do estudo de caso em um Laboratório de Inovação dentro de apenas uma tecnologia, teve o objetivo de apresentar os impactos da tecnologia 4.0 dentro da cocriação de valor, através do mesmo, foi possível identificar as oportunidades e os desafios encontrados para se implementar a Indústria 4.0 na cocriação de valor em serviços. Por fim, Bonamigo et al. (2020) conclui que a cocriação de valor foi um fator principal para criar sua operacionalidade e obter vantagens, ainda que existam pontos para melhorar a gestão de riscos.

Assandre et al. (2020) destacam o grande poder que o big data analytics tem em melhorar sistemas de medição de desempenho das empresas. Para isto, foi realizado uma revisão sistemática da literatura, onde o foco foi em artigos com estudos empíricos e obteve-se resultados quanto a função de alterar os sistemas, armazenamentos, análise de grandes banco de dados, sua capacidade de ser versátil em questões de formatos e fontes e como as empresas conseguem implantá-la mesmo com os desafios encontrados, além expor outros pontos positivos quanto a capacidade de processar dados e disseminar informações instantaneamente, entre outros pontos.

Neto et al. (2020) realizaram uma análise bibliométrica para realizar um levantamento do que já foi produzido e publicado no que diz respeito a gestão de manutenção no setor de óleo e gás, isto se deu, devido a busca constante por melhor produtividade das empresas nesse setor, dando ênfase no setor de manutenção, pois as evidências, também, que a busca por diminuição de custos, diminuição de paradas de produção estão entre os principais focos, realizar estas 
atividades no menor tempo possível. Por fim, o estudo conclui que a partir do ano de 2017 o número de publicações relacionados ao tema cresceram significativamente, destacando como o país mais que contribui, o Estados Unidos, entretanto, a busca por inteligência computacional dentro do ramo está em crescimento.

Elero e Ferreira (2020) destacaram em seu estudo de caso a importância da Gestão da Qualidade dentro das organizações, através desse pressuposto foi possível analisar o mercado competitivo e aprimorar o processo da indústria em questão. Para isso, foi desenvolvida os indicadores e um Dashboard para a comunicação dos dados da indústria, disponibilizando gráfico de controle e medidas de perdas, com a capacidade de atualização em tempo real. Todavia, a aplicação da ferramenta obteve bons resultados em sua implantação e bem recebido pela empresa.

Franco et al. (2020) desenvolveram uma revisão sistemática da literatura, onde foi possível analisar a aplicação das tecnologias da Indústria 4.0 nas áreas da Engenharia de Produção, com o intuito de detalhar pontos nesse âmbito de investigação. Foram analisados 68 artigos e os resultados confirmam que a implantação das tecnologias 4.0 vem crescendo a cada ano. A área que mais se destacou com o número de estudo empíricos foi Engenharia de Operações e a tecnologia que mais destacou foi Internet das coisas, além de mostrar os setores e países que mais se destacam dentro dessa realidade. O estudo exibe os impactos econômicos e sociais com a implementação dessas ferramentas.

Gambi e Lizarelli (2020) estudaram a influência das variáveis abordagens da Melhoria Contínua têm na adoção de Tecnologias 4.0, pontos foram abordados com o objetivo de enfatizar a relação entre essas duas ferramentas, a fim de alcançar resultados que comprovem os pontos positivos. Dessa forma, foi realizado uma pesquisa survey em empresas de manufatura de oito países e feito a análise dos dados e, concluiu que as variáveis abordagens da Melhoria Contínua no uso da Tecnologia 4.0 têm um efeito positivo com relação a manufatura e inovação. Entretanto, para que isso venha acontecer é necessário que os gestores alinhem suas abordagens de melhoria contínua com as tecnologias 4.0.

Lego e De Mattos (2020) desenvolveram um estudo de caso em uma empresa do segmento de tecnologia, onde o objetivo foi, através de um estudo qualitativo, mapear relações entre Internet das Coisas (Internet of Things - IoT) e 
manufatura ágil. Nesse contexto, foi implementado um projeto de transformação digital no processo de qualidade, onde os resultados da loT satisfizeram o monitoramento, oferecendo disponibilidade, aumentando a flexibilidade e velocidade nas respostas. Por fim, o estudo pôde concluir que mesmo que a aplicação esteja em estágio inicial, tende a contribuir muito no planejamento para uma possível aplicação na prática, auxiliando os colaboradores na implantação da tecnologia loT.

Medeiros et al. (2020) abordaram em seu estudo as dificuldades encontradas pelas organizações no mercado competitivo e paralelo isso, a importância que se tem em se ter integrado ao processo a manufatura enxuta (ME) com a indústria 4.0 (14.0). Desta forma, os autores realizaram uma revisão bibliográfica sistemática referente ao uso das tecnologias da indústria 4.0 e as prática da produção enxuta, onde foram identificados pontos na literatura e as expressões dos possíveis temas da pesquisa através do desenvolvimento de um portfólio bibliográfico de publicações. Através de revisões sistemáticas e base de dados foram desenvolvidas análises quantitativas bibliométricas, qualitativas e de conteúdo. A partir da organização do portfólio através de parâmetros, foi possível apontar que as deficiências das práticas convencionais podem ser superadas e evidencia que a combinação entre produção enxuta e indústria 4.0, quando integradas, melhoram a produtividade, eliminam resíduos e se flexibilizam quanto a demandas específicas. Por fim, o estudo conclui que de acordo com os resultados obtidos foi possível construir uma gama de referência do estado da arte sobre o tema.

Para entender os impactos da Indústria 4.0 dentro das organizações quanto ao capital humano, Mendes et al. (2020) propuseram uma pesquisa com o objetivo de identificar as mudanças observadas nos profissionais quando implantado tecnologias da Indústria 4.0. Neste contexto, foi observado que embora a Indústria 4.0 traga diversos benefícios, por outro lado, existem exigências para sua implementação, tanto nas organizações (infraestrutura) quanto ao capital humano, todavia, através de uma pesquisa qualitativa, por meio de uma revisão bibliográfica, buscou-se entender melhor o perfil profissional e como resultado, obteve-se dezoito tecnologias e oito competências relacionadas a indústria 4.0.

Oliveira et al. (2020) estudaram o Planejamento e Controle de Produção adotado por uma empresa multinacional prestadora de serviços de manutenção e, 
através de um estudo de caso, de caráter qualitativo e exploratório, identificar os problemas e suas causas e as possíveis melhorias dentro do modelo adotado. Dentro deste contexto, foram realizadas entrevistas presencialmente com gestores do setor, a fim de mitigar os problemas e as possíveis melhorias para se aplicar. Como resultado, observou que os problemas se concentram nas corretivas, cumprimento de prazos entre outros.

Reis e Shirabayashi (2020) identificaram como as indústrias brasileiras têm se comportado quanto a implantação da Indústria 4.0, dando ênfase na aplicação da IoT. Para isto, foi desenvolvido uma revisão sistemática da literatura referente aos últimos 5 anos, com o intuito de identificar tais aplicações. Neste contexto, os resultados mostraram que a loT cresce com um grande potencial nas indústrias brasileiras e se sabe que sua aplica se torna um diferencial competitivo no mercado, mas ainda assim, sua aplicação se encontra incipiente em alguns setores.

Generoso et al. (2020) destacaram a cocriação de valor em serviços e estudam sua interação com Internet das Coisas (IOT), de modo a identificar os benefícios desta tecnologia para tal. Nesse contexto, foi desenvolvido uma pesquisa exploratória, com o intuito de apontar as vantagens e os desafios encontrados decorrentes da aplicação da loT.

Dentro do contexto de que o aumento da aplicação das tecnologias na cadeia produtiva seja de fato necessário, Silva e Barbalho (2020) desenvolveram um trabalho onde enfatizam que nos últimos 5 anos, para acompanhar este aumento, diversos modelos têm sido desenvolvidos, com a ideia de avaliar o nível de maturidade que as empresas têm para suportar ou não esta revolução. Desta forma, o trabalho foi desenvolvido com o objetivo de destacar os principais modelos de maturidade para indústria 4.0, além de mostrar a relação dos profissionais com essa novidade e os responsáveis por adotaram estas ferramentas como método de solução para problemas locais.

Silva et al. (2020) destacam a intensificação da quarta revolução industrial cada vez mais constante no dia a dia, levanto pontos que a indústria 4.0 traz em seus conceitos, além de enfatizar os efeitos percebidos no que diz respeito a funcionário. Para desenvolvimento do estudo foi realizado uma busca sistemática em artigos científicos, com o objetivo de explicar as tecnologias, a organização (que a recebe) e o funcionário. 
Sousa et al. (2020) abordam em seu trabalho a importância da Internet das Coisas (IOT) dentro da indústria 4.0 e o porquê. Para tal, foi explorado a aplicação desta tecnologia em smartphones, com o intuito de destacar a sua funcionalidade dentro do aparelho. Os resultados obtidos com essa aplicação se deram de forma positiva, onde a integração de ambos foi observada através de monitoramento de condições.

\section{CONSIDERAÇÕES FINAIS}

O estudo em questão obteve informações relevantes referente ao tema de pesquisa aplicação dos recursos da tecnologia 4.0. Os objetivos foram alcançados, de forma que, ao final da aplicação da metodologia ProKnow-C, obteve-se um portfólio de 22 artigos de reconhecimento científico e publicados recentemente.

De posse dos 22 artigos integrantes, realizou-se um estudo quantitativo e qualitativo do portfólio bibliográfico onde foi possível visualizar diversas informações importantes

O caminho para selecionar os 22 artigos foi realizado em um eixo de pesquisa, onde selecionou o portfólio bibliográfico e, posteriormente, fez a análise bibliométrica nos artigos das bases de dados que mais estavam relacionadas com o tema. Na seleção do portfólio, o ENEGEP se destaca com o número de publicações dentro do portfólio, com 14 artigos no ano de 2020. Esse dado reforça a importância que assuntos relacionados ao tema aplicação dos recursos da tecnologia 4.0 tiveram durante o período analisado. Nesse contexto, se destaca, também, artigo "Indústria 4.0: contribuições para o setor moderno" publicado pela ENEGEP citado 15 vezes quanto ao reconhecimento científico. O estudo bibliométrico, trouxe destaque a origem dos artigos das referências do portfólio, sendo 251 originados de revistas, nesse sentido, mostrou o grau de relevância deste tipo de publicação quanto tema de pesquisa.

O método ProKnow-C faz com que o processo seja sistematizado, ainda que exista a subjetividade na seleção dos artigos, faz parte do processo, a partir de que o autor tenha seu próprio interesse e objetivo referente ao tema de pesquisa. Através da aplicação do método dentro do tema aplicação de recursos da tecnologia 4.0, foi possível concluir, que diante dos resultados quantitativos obtidos e o nível de relevância dos artigos selecionados, se trata de uma ferramenta extremamente 
importante na procura e seleção de artigos referente ao tema de pesquisa, isto é, devido ao seu alto grau de sistematização na pesquisa. Nesse sentido, sua sistematização se torna necessário quando parte do princípio de que seja necessário simplificar e organizar os meios de pesquisa, consequentemente, aumentando o conhecimento do pesquisador quanto ao tema, além de, possibilitar a justificativa das referências utilizadas na pesquisa.

Dentre os resultados obtidos, a identificação dos periódicos que mais publicam, destaca-se a aceitação do tema quanto ao meio de pesquisa, enfatizando as diversas possibilidades de melhorias que se tem ao se utilizar tecnologia 4.0. Servindo como material de referência para desenvolver estudos no âmbito, disponibilizando como material de estudo no que diz respeito a implantação dos recursos da tecnologia $4.0 \mathrm{em}$ problemas recorrentes dentro do chão de fábrica e, os resultados que se pode obter com sua implantação. Dessa forma, como engate para futuras pesquisas e estudos relacionados a aplicação dos conceitos da indústria 4.0, sugere-se os temas: "Etapas para implantação da indústria 4.0", "Aplicação das tecnologias da indústria 4.0 na Engenharia de produção", "Gestão do conhecimento e indústria 4.0" e "Indústria 4.0: contribuições para o setor produtivo moderno".

\section{REFERÊNCIAS}

ANDRADE, W.; MEZA, E.; VIANNA, D.; VIANNA, M. A Importância da Manutenção na Indústria do Petróleo \& Gás. In: XL ENCONTRO NACIONAL DE ENGENHARIA DE PRODUÇÃO, 40, 2020, Foz do Iguaçu, PR. Anais... Foz do Iguaçu: ABEPRO, 2020.

ASSAD, N. E. T. O. A busca de uma identidade para a indústria 4.0. In: XXXVII ENCONTRO NACIONAL DE ENGENHARIA DE PRODUÇÃO, 37, 2017, Joinville, SC. Anais... Joinville: ABEPRO, 2017.

ASSANDRE, J.; MARTINS, R. O uso de big data analytics em sistemas de medição de desempenho: uma revisão de estudos empíricos. In: XL ENCONTRO NACIONAL DE ENGENHARIA DE PRODUÇÃO, 40, 2020, Foz do Iguaçu, PR. Anais... Foz do Iguaçu: ABEPRO, 2020.

BONAMIGO, Andrei; WERNER, Steffan Macali; ROSA, Louise Generoso. Engenharia de Serviços: Os Impactos da Industria 4.0 no Contexto da cocriação de valor em Serviços Industriais. In: XL ENCONTRO NACIONAL DE ENGENHARIA DE PRODUÇÃO, 40, 2020, Foz do Iguaçu, PR. Anais... Foz do Iguaçu: ABEPRO, 2020.

CORDEIRO, G. A. et al. Etapas para implantação da Indústria 4.0: uma visão sob aspectos estratégicos e operacionais In: XXXVII ENCONTRO NACIONAL DE ENGENHARIA DE PRODUÇÃO, 37, 2017, Joinville, SC. Anais... Joinville: ABEPRO, 2017. 
DA SILVA, Isaac Ambrósio; BARBALHO, Sanderson César Macêdo. Modelos de maturidade para indústria 4.0-estudos de caso. In: XL ENCONTRO NACIONAL DE ENGENHARIA DE PRODUÇÃO, 40, 2020, Foz do Iguaçu, PR. Anais... Foz do Iguaçu: ABEPRO, 2020.

DE CARVALHO, G. D. G., SOKULSKI, C. C., DA SILVA, W. V., DE CARVALHO, H. G., DE MOURA, R. V., DE FRANCISCO, A. C., \& DA VEIGA, C. P. Bibliometrics and systematic reviews: A comparison between the Proknow-C and the Methodi Ordinatio. Journal of Informetrics, 14(3), p. 101043, 2020.

ELERO, M.; FERREIRA, M. Desenvolvimento de indicadores e dashboard para gestão da qualidade em uma indústria de produtos eletrônicos. In: XL ENCONTRO NACIONAL DE ENGENHARIA DE PRODUÇÃO, 40, 2020, Foz do Iguaçu, PR. Anais... Foz do Iguaçu: ABEPRO, 2020.

FRANCO, D.; QUEIROZ, G.; MOTA, R.; MEDEIROS, N.; FILHO, M. Aplicação das tecnologias da Indústria 4.0 na Engenharia de produção: uma revisão sistemática da literatura. In: XL ENCONTRO NACIONAL DE ENGENHARIA DE PRODUÇÃO, 40, 2020, Foz do Iguaçu, PR. Anais... Foz do Iguaçu: ABEPRO, 2020.

GAMBI, L.; LIZARELLI, F. Efeitos das abordagens de melhoria contínua no uso de tecnologias 4.0 para a manufatura e inovação. In: XXVII SIMPÓSIO DE ENGENHARIA DE PRODUÇÃO, 27, 2020, Bauru, SP. Anais... Bauru: SIMPEP, 2020.

LEGO, Lalesca Lopes; DE MATTOS, Claudia Aparecida. O papel da Internet das Coisas (loT) nas práticas de manufatura ágil: uma análise da interação do modelo conceitual de manufatura ágil com as categorias de aplicativos da IOT. In: XL ENCONTRO NACIONAL DE ENGENHARIA DE PRODUÇÃO, 40, 2020, Foz do Iguaçu, PR. Anais... Foz do Iguaçu: ABEPRO, 2020.

MEDEIROS, E.; BESSA, L.; JÚNIOR, C.; HATAKEYAMA, H. Revisão Sistemática do Uso Integrado das Tecnologias da Indústria 4.0 e Práticas da Produção Enxuta. In: XL ENCONTRO NACIONAL DE ENGENHARIA DE PRODUÇÃO, 40, 2020, Foz do Iguaçu, PR. Anais... Foz do Iguaçu: ABEPRO, 2020.

MENDES, B.; CUNHA, R.; PEREIRA, A.; BOUYER, G. Gestão do Conhecimento e Indústria 4.0: Competências Requeridas aos Profissionais Inseridos neste Contexto. In: XL ENCONTRO NACIONAL DE ENGENHARIA DE PRODUÇÃO, 40, 2020, Foz do Iguaçu, PR. Anais... Foz do Iguaçu: ABEPRO, 2020.

NETO, B. A. D.; TEIXEIRA, Y. P.; DA HORA, H. R. M. Mineração de dados em gestão da manutenção: uma análise bibliométrica em manifestos da indústria de óleo e gás. In: XXVII SIMPÓSIO DE ENGENHARIA DE PRODUÇÃO, 27, 2020, Bauru, SP. Anais... Bauru: SIMPEP, 2020.

OLIVEIRA, T.; SOUSA, M.; DE MELO, M.; LIPPI, M. Análise do planejamento e controle da produção em uma empresa prestadora de serviços terceirizados de manutenção segundo o modelo MRPII. In: XL ENCONTRO NACIONAL DE ENGENHARIA DE PRODUÇÃO, 40, 2020, Foz do Iguaçu, PR. Anais... Foz do Iguaçu: ABEPRO, 2020.

QUEIROZ, Laura Michelle dos Anjos. Planejamento e controle da manutenção aplicados ao processo de manufatura no ramo alimentício. In: XXXV ENCONTRO 
NACIONAL DE ENGENHARIA DE PRODUÇÃO, 35, 2015, Fortaleza, CE. Anais... Fortaleza: ABEPRO, 2015.

REIS, J.; SHIRABAYASHI, J. Aplicações da Internet das Coisas na Indústria Brasileira: Uma revisão sistemática. XL ENCONTRO NACIONAL DE ENGENHARIA DE PRODUÇÃO, Foz do Iguaçu, Paraná, 2020.

ROSA, L.; ROSA, L. As Contribuições da Internet das Coisas na Co-criação de Valor em Serviços. In: XL ENCONTRO NACIONAL DE ENGENHARIA DE PRODUÇÃO, 40, 2020, Foz do Iguaçu, PR. Anais... Foz do Iguaçu: ABEPRO, 2020.

RÜSSMANN, Michael et. al. Industry 4.0: The Future of Productivity and Growth in Manufacturing Industries, Boston Consulting Group (BCG), 2015.

SIGAHI, TFAC; ANDRADE, BC de. A Indústria 4.0 na perspectiva da engenharia de produção no Brasil: levantamento e síntese de trabalhos publicados em congressos nacionais In: XXXVII ENCONTRO NACIONAL DE ENGENHARIA DE PRODUÇÃO, 37, 2017, Joinville, SC. Anais... Joinville: ABEPRO, 2017.

SILVA, EP da et al. Gestão da manutenção indústria em transição para a indústria 4.0: controle mobile, considerações sobre esta nova tecnologia. In: XXXVII ENCONTRO NACIONAL DE ENGENHARIA DE PRODUÇÃO, 37, 2017, Joinville, SC. Anais... Joinville: ABEPRO, 2017.

SILVA, M.; SILVA, L. Conceitualização da Indústria 4.0: uma análise utilizando revisão sistemática da literatura. In: XL ENCONTRO NACIONAL DE ENGENHARIA DE PRODUÇÃO, 40, 2020, Foz do Iguaçu, PR. Anais... Foz do Iguaçu: ABEPRO, 2020.

SOUSA, T.; IBUSUKI, U.; CONTE, E. Estudo de Aplicabilidade de Internet of Things por smartphones: Análise de movimentação de usuários. In: XL ENCONTRO NACIONAL DE ENGENHARIA DE PRODUÇÃO, 40, 2020, Foz do Iguaçu, PR. Anais... Foz do Iguaçu: ABEPRO, 2020.

SOUZA, E.; JUNIOR, SJC; NETO, GGD. Indústria 4.0: contribuições para setor produtivo moderno. In: XXXVII ENCONTRO NACIONAL DE ENGENHARIA DE PRODUÇÃO, 37, 2017, Joinville, SC. Anais... Joinville: ABEPRO, 2017. 